\title{
sciendo
}

DOI: $10.2478 / \mathrm{fv}-2019-0029$

FOLIA VETERINARIA, 63, 3: 66-71, 2019

\section{HIGHLY PATHOGENIC AVIAN INFLUENZA H5N1 (HPAI/H5N1) VIRUS SEARCH FROM WILD BIRDS IN GHANA}

\author{
Suu-Ire, R. ${ }^{1}$, Awuni, J. ${ }^{2}$, Benia. P. ${ }^{3}$, Kia, G. ${ }^{4}$ \\ ${ }^{1}$ School of Veterinary Medicine, University of Ghana \\ ${ }^{2}$ Accra Veterinary Laboratory, Veterinary Services Directorate, MOFA \\ ${ }^{3}$ Accra Zoological Gardens, Forestry Commission \\ Ghana \\ ${ }^{4}$ Ahmadu Bello University Zaria \\ Nigeria
}

suuire@gmail.com

\begin{abstract}
Highly pathogenic avian influenza (AI) disease has occurred in many countries globally adversely affecting domestic poultry production. Ghana recorded her first outbreak of a highly pathogenic avian influenza (HPAI) in 2007 on a small scale commercial farm in Tema. Since then, there have been numerous outbreaks. The source of these outbreaks is not conclusive. The role of wild birds in the epidemiology of avian influenza outbreaks in Ghana is not known. This study sought to investigate the role of wild birds in the outbreaks of Highly Pathogenic Avian Influenza (HPAI H5N1) in Ghana, particularly in Southern Ghana. Wild birds were trapped and sampled through mist netting. The faecal and tracheal samples were analysed using a One-Step Real Time Reverse Transcription Polymerase Chain reaction (RT-PCR) with primer sets targeting the matrix protein gene of the Avian influenza virus. Sera samples were subjected to multispecies competitive Enzyme Linked Immunosorbent Assay (ELISA) for anti-AI virus antibodies. Three hundred and twenty two (322) wild birds were trapped and sampled.
\end{abstract}

Birds sampled included $87.3 \%(281 / 322)$ resident birds and $12.7 \%(41 / 322)$ migratory birds. The migratory birds included intra-African migrants $12.2 \%(5 / 41)$ and Palearctic migrants $87.8 \%(36 / 41)$. Avian influenza virus and antibody were neither detected in these swabs nor sera samples, respectively. The study documented the absence of $\mathrm{AI}$ in resident and migrant wild birds in the study area and suggest that wild birds may not be responsible for the outbreaks of AI in the poultry. However, sustained surveillance is recommended to ascertain a nationwide successful prevention and control strategy to stay the tide of any future intruding AI outbreaks.

Key words: Highly Pathogenic Avian Influenza Virus (HPAI H5N1); migratory birds; resident birds; southern Ghana; wild birds

\section{INTRODUCTION}

Globally, wild birds play an important role in the ecosystem such as, forest regeneration through plant pollination 
and seed dispersal and provide ecotourism [15]. Wild birds are natural reservoirs for avian influenza (AI) viruses and play a major role in the evolution, maintenance, and spread of AI viruses [2,14]. They host a wide diversity of subtypes, and provide a dynamic population for viral evolution and transmission to domestic flocks and mammals (12). Wild birds such as migratory birds have been implicated in the transmission of highly pathogenic avian influenza (bird flu), West Nile virus and so many others [16]. Studies have shown that low pathogenic avian influenza virus has been detected in waterfowl and shorebirds species [7] and highly pathogenic avian influenza virus has been detected in wild birds, especially ducks [9]. Varied strains of avian influenza virus have been detected in many countries, H5N8 in wild ducks in Netherlands [9], H5N1 was detected in wild bird in Bavaria [10], H5N8 has been confirmed in Nigeria [18].

Surveillance for diseases including AI in wild birds is sporadic, geographically biased, and often limited to the last outbreak virus. Ghana reported several outbreaks of highly pathogenic avian influenza (HPAI H5N1) in the southern and middle belts of the country. The first outbreak of AI (H5N1) was in 2007 on a small scale commercial poultry. Several outbreaks have occurred in Ghana after the first outbreak. There have been outbreaks of HPAI H5N1 in 2015 [5] and H9N2 subtype reported in poultry in Ghana in 2019 [1]. The outbreaks affected the poultry industry as about 40,000 birds were culled. Other economic loss to Ghana include the cost in compensation to the affected farmers, disease control, capacity building in diagnosis and surveillance [5]. The source of these outbreaks is not conclusive. Many projections to the source of outbreaks have been made. Wild birds have been implicated, however, the role of wild birds in the epidemiology of avian influenza outbreaks is not known in Ghana. More so, the source of the first outbreak is still not clear [16].

The aim of this study was to investigate the role of wild birds in the outbreaks of Highly Pathogenic Avian Influenza (HPAI H5N1) in Ghana, particularly in Southern Ghana.

\section{MATERIALS AND METHODS}

\section{Study Area}

The study locations were selected based on previous AI outbreaks in Ghana in Southern Ghana (Fig. 1) which in-

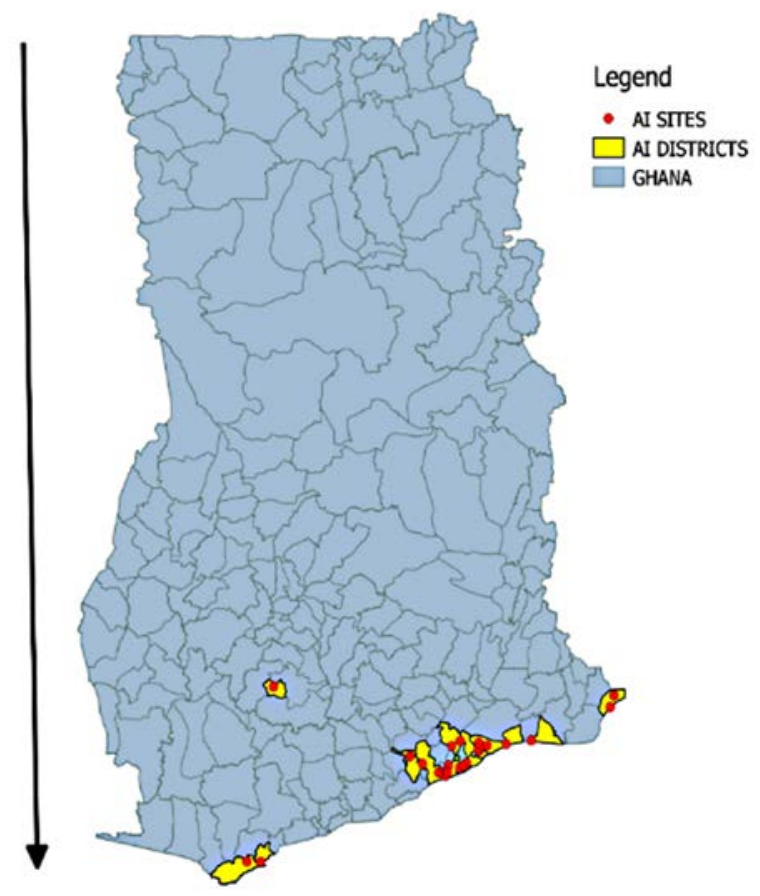

Fig. 1. Map of Ghana showing the Avian Influenza Outbreak Sites and Districts

cluded the Greater Accra Region (Ayi Mensah, Achimota and Densu Delta Ramsar Site) and Eastern Region (AssinFoso, Akim-Oda and Brema Asikuma). Samples were collected from free ranging healthy wild birds and quarantined wild birds.

\section{Wild bird trapping and sample collection in the field}

Mist net trapping was done in the early hours of the nights and mornings targeting the peak period of the wild bird activities. These ready opened trap nets were visited and inspected regularly at intervals of 30 minutes, to check for captures. Captured birds were immediately removed to avoid struggles and injuries. Birds were kept in cotton bird bags in a shady field camp until sampled. They were restrained by trained assistants using the ringer hold's method [3]. Whole blood $(0.5 \mathrm{ml})$ from the jugular vein or wing vein [6], as well as cloacal and tracheal swabs were collected from each bird. After sampling, the birds were safely released back into the wild. Tracheal and faecal swabs were placed in tubes containing viral transport medium (Thermo Scientific $^{\mathrm{TM}}$ Sterilin $^{\mathrm{TM}}$ UTM (Universal Transport Medium). Whole blood was obtained from the jugular vein or wing vein [8] using 27 G $1 / 2$ needle and a $1 \mathrm{ml}$ syringe and placed in non-heparinized capillary tubes. A total of 
322 wild birds were sampled by the end of the study. The wild birds sampled from the various sampling sites included in the surveillance are in Fig. 2.

Swabs from the field were immediately placed in a thermos flask containing ice packs and transported to the Accra Veterinary Laboratory. The swabs and sera samples were stored at $-18^{\circ} \mathrm{C}$ [17] at the Accra Veterinary Laboratory until use. The sera were harvested into a clean plain tube, covered and labelled appropriately.

\section{Sample analyses}

Real time RT-PCR and multispecies competitive Enzyme Linked Immunosorbent Assay (ELISA) were employed in this study.

\section{Molecular detection}

RNA Extraction: Up to five cloacal and throat samples were pooled based on species and sampling location. RNA was extracted using purification of viral RNA spin protocol with QIAamp viral RNA Mini kit (Q i a g e n, 2010).

Real time RT-PCR: The pooled samples were tested for the highly conserved gene of Influenza type A gene. The determinations of positive pools were done individually and subsequently tested for H5. Primers and probes specific to influenza A matrix gene were used in conjunction with the PikoReal Time PCR system (Life Technologies Corp, Carlsbad, CA) (Table 1) with thermocycler conditions (as in Table 2) and described by L o r e $\mathrm{n} \mathrm{z}$ et al. [11].

\section{Serology Test}

The presence of antibodies against the nucleoproteins and matrix proteins of avian influenza virus were determined by ELISA Test using the Flocktype AIV Ab ELISA kit (Lot No: 254111033) produced by Qiagen (Germany).

\section{Ethical Clearance}

The work was undertaken as part of government official veterinary surveillance during the AI outbreak. The first author was the Government Wildlife Veterinarian of Wildlife Division of the Forestry Commission of Ghana and has

Table 1. PCR primers, probe, and sequence

\begin{tabular}{ccc}
\hline Specific test & $\begin{array}{c}\text { Primer/ } \\
\text { probe }\end{array}$ & Sequence 5囚-3囚 \\
\hline M25-F & AGATGAGTCTTCTAACCGAGGTCG \\
$\begin{array}{c}\text { Influenza type } \\
\text { A M-gene }\end{array}$ & M124-R & TGCAAAAACATCTTCAAGTCTCTG \\
& M64 & FAM-TCAGGCCCCCTCAAAGCCGA-TAMRA \\
\hline
\end{tabular}

Table 2. Thermocycling conditions for M-gene

\begin{tabular}{cccc}
\hline RT & $\begin{array}{c}\text { Initial } \\
\text { Denaturation }\end{array}$ & Denaturation & Annealing \\
\hline $50^{\circ} \mathrm{C}$ & $95^{\circ} \mathrm{C}$ & $94^{\circ} \mathrm{C}$ & $60^{\circ} \mathrm{C}$ \\
$20 \mathrm{~min}$ & $15 \mathrm{~min}$ & $45 \mathrm{sec}$ & $45 \mathrm{sec}$ \\
& & $40 \mathrm{Cycles}$ & \\
\hline
\end{tabular}

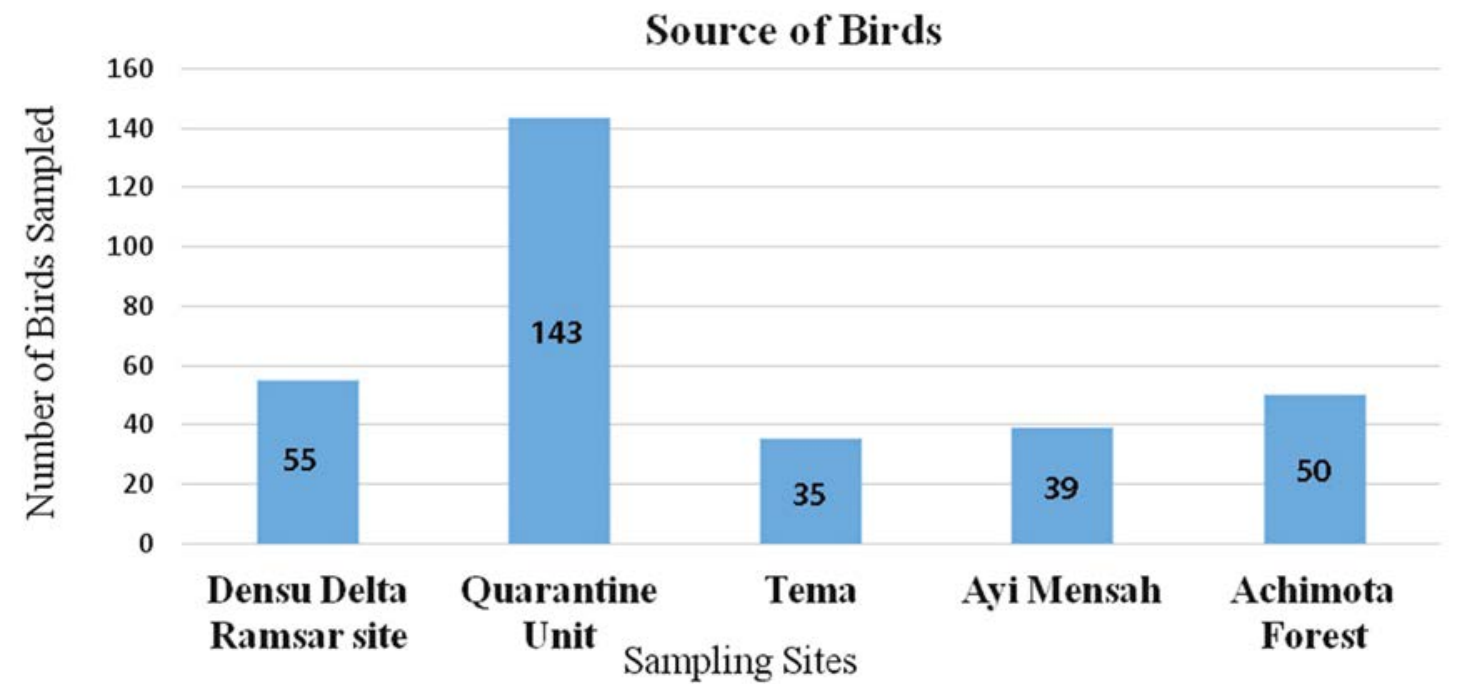

Fig. 2. Locational distribution of wild birds in previous Avian Influenza outbreak sites in Ghana 
possessory right to the data. No written permission was needed and hence not issued.

\section{RESULTS}

\section{Descriptive characteristics of wild birds}

The classification of birds by location, migratory status and the bird species sampled are presented in Figures 2, 3 and 4 , respectively. The majority (45\% (145/322)) of the wild birds in this study were quarantined birds from the eastern region of Ghana (Fig. 2). These birds were legally collected by Wildlife export facilities for export (Wildlife business). The total numbers of wild birds for the study were 322. Those categorized as Ghana resident birds were $87.3 \%(281 / 322)$ while the remaining $12.7 \%$ (41/322) were migratory birds. About $12.2 \%$ (5/41) of the 41 migratory birds, were intra-African migrants and $87.8 \%$ (36/41) were Palearctic migrants (Fig. 3). We trapped and sampled 8 migratory species overwintering in Ghana (Fig. 4).

\section{Reverse Transcription Polymerase Chain Reaction}

The M-gene was amplified from the positive control tested by PikoRT-PCR. Detectable levels of M-gene were recorded at 28.31 cycles. The maximum amplification was recorded at 2400 relative fluorescence units (RFU).

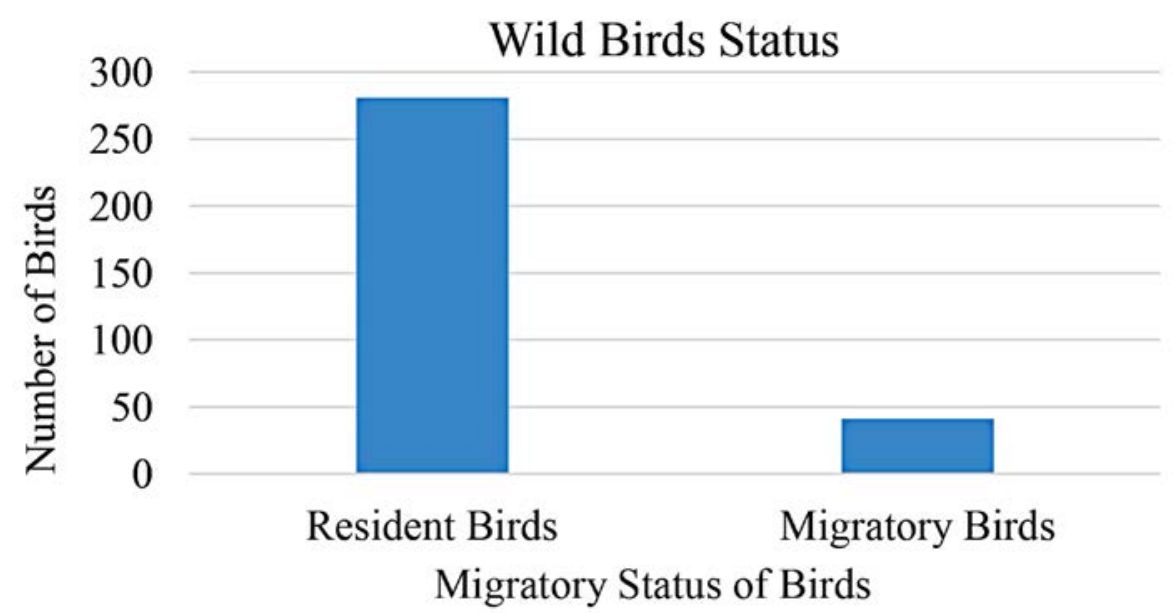

Fig. 3. Distribution of resident and migratory wild birds from previous Avian Influenza outbreak sites in Ghana

\section{Species of Migratory Birds Sampled}

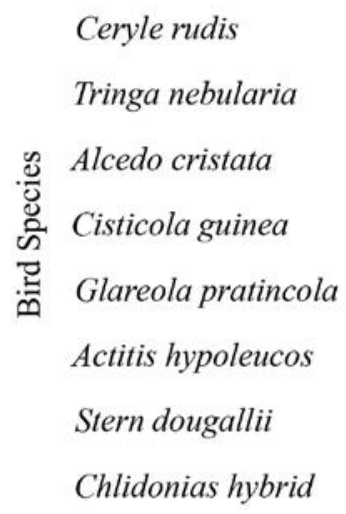

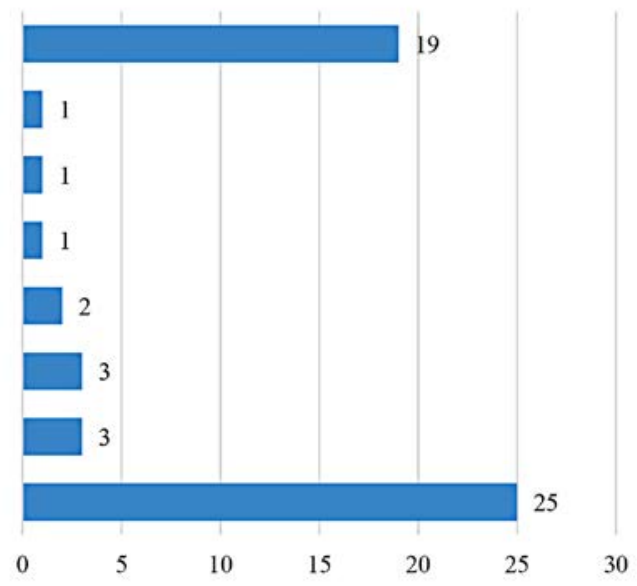

Number Sampled

Fig. 4. Species variation of wild birds sampled from previous Avian Influenza outbreak sites in Ghana 
Influenza Type A M-gene was not amplified from the negative control tested by PikoRT-PCR. Internal amplification control recorded a maximum amplification of about 55 RFU. No influenza Type A M-gene was amplified from the 322 swab samples tested by PikoRT-PCR. Internal amplification control of all the samples were less than that recorded in the positive control sample.

Three hundred and eighteen (318) sera were collected for testing. No antibody was detected in all sera (Table 3 ).

\section{DISCUSSION}

Studies reported in other African countries and Europe support the hypothesis that wild birds are carriers of avian influenza viruses and play a role in the epidemiology of avian influenza viruses $[2,14]$.

This is not evident in this study given the time frame and wild bird species that were sampled. Also, given the fact that $12 \%$ of the wild birds in this study are palearctic migrants, there was no evidence of avian influenza virus as well as antibodies to signify exposure.

The failure to detect AI virus and the absence of the AI antibodies may be a true picture of AI in wild birds in Ghana in the absence of other factors such as diagnostic failure probably because of lack of validation of the method for wildlife samples to eliminate false negative results or poor collection and/or handling of samples on the field or during storage prior to sample analysis.

There were no detectable antibodies in the sera of the birds (Table 3 ). The serological prevalence values of the samples were below 0.3 . Thus, these wild bird species may not have been exposed to avian influenza virus and neither the HPAI H5N1 virus.

Influenza Type A M-gene was amplified from the positive control and none was amplified from the negative control. This indicated that the primers and probes for detect-

Table 3. Enzyme linked immunosorbent assay for HPAI H5N1 antibody in resident and migrant wild birds in Ghana

\begin{tabular}{lccc}
\hline \multicolumn{1}{c}{ Samples } & Number & Positives & Prevalence \% \\
\hline Throat samples & 322 & 0 & 0 \\
Cloacal samples & 322 & 0 & 0 \\
Sera & 318 & 0 & 0 \\
\hline
\end{tabular}

ing the Influenza type A M-gene and the control samples were valid. Cloacal and throat swab samples from all the wild bird species that were sampled tested negative for influenza Type A virus M-gene. Hence, no influenza virus, both HPAI and LPAI was found in the wild bird species sampled, nor in samples from AI outbreaks areas in Ghana, as similarly documented by F e $\mathrm{n} t \mathrm{e} n \mathrm{~g}$ et al. [4]. The outcome of this work is also not surprising because it is also consistent with the report of the absence of $\mathrm{H} 5 \mathrm{~N} 1$ in wild birds in Europe [13].

\section{CONCLUSIONS}

There was no evidence of Avian Influenza virus or any antibodies in all of the wild birds sampled from areas where AI previously occurred in Ghana. The continued AI surveillance in all seasons nationwide is needed in order to be able to establish the status and/or role of wild birds in relation to AI transmission so as to aid the prevention and control of AI programs nationwide and by extension, globally.

\section{ACKNOWLEDGEMENTS}

The Directorate of Veterinary Services and Staff especially of the Accra Veterinary Laboratory were very supportive in laboratory analysis of the samples. Dr. Sherry Mawuko Johnson read the manuscript and provided useful comments. The authors wish to thank the Wildlife Division of the Forestry Commission of Ghana for waiving the cost of providing a permit for the study and providing Field Staff to assist with the field study.

\section{REFERENCES}

1. Awuni, J. A., Bianco, A., Dogbey, O. J., Fusaro, A., Yingar, D. T., Salviato, A., et. al., 2019: Avian influenza H9N2 subtype in Ghana: virus characterization and evidence of co-infection. Avian Pathol., 48, 5, 470-476. DOI: 10.1080/03079457. 2019.1624687.

2. Caron, A., Cappelle, J., Gaidet, N., 2016: Challenging the conceptual framework of maintenance hosts for influenza A viruses in wild birds. J. Appl. Ecol., 54, 681-640. DOI: 10. 1111/1365-2664.12839. 
3. Fair, J. M., Paul, E., Jones, J., Barrett Clark, A., Davie, C. Kaiser, G., 2010: Guidelines to the Use of Wild Birds in Research. Washington, D. C.: Ornithological Council, 3rd edn., $215 \mathrm{pp}$.

4. Fenteng, D. E., 2010: Epidemiology of Avian Influenza in Domestic Poultry and Wild Birds in the Tema Metropolis. Oral Communication.

5. Food and Agriculture Organisation of the United Nations, 2016: Controlling Highly Pathogenic Avain Influenza Outbreaks in Ghana-TCP/GHA/3505.

6. Grant, K. R., Johnston, M.S., 2009: Avian Venipuncture. NAVC, Clinician Brief, 5-7.

7. Grillo, V., Arzey, K., Hansbro, P., Hurt, A., Warner, S., Bergfeld, J., et al., 2015: Avian influenza in Australia: a summary of 5 years of wild bird surveillance. Aust. Vet. J., 93, 11, 387-93. DOI: 10.1111/avj.12379.

8. Hassan, M. M., Hoque, M. A., Debnath, N. C., Yamage, M., Klaassen, M., 2017: Are poultry or wild birds the main reservoirs for avian influenza in Bangladesh? Ecohealth, 14, 3 , 490-500. DOI: 10.1007/s10393-017-1257-6.

9. Kleyheeg, E., Slaterus, R, Bodewes, R., et al., 2017: Deaths among wild birds during Highly Pathogenic Avian Influenza A(H5N8) virus outbreak, the Netherlands. Emerg. Infect. Dis., 23, 12, 2050-2054. DOI: 10.3201/eid2312.171086.

10. Lang, V., Rinder, M., Hafner-Marx, A., Rabl, S., Bogner, K. H., Neubauer-Juric, A., Büttner, M., 2010: Avian influenza A virus monitoring in wild birds in Bavaria: occurrence and heterogeneity of $\mathrm{H} 5$ and $\mathrm{N} 1$ encoding genes. Zoonoses and Public Health, 57, 7-8, e184-194. DOI: 10.1111/j.18632378.2010.01326.x

11. Lorenz, T. C., 2012: Polymerase chain reaction: basic protocol plus troubleshooting and optimization strategies. J. Vis. Exp., 63, e3998. DOI:10.3791/3998.
12. Machalaba, C. C., Elwood, S. E., Forcella, S., et al., 2015: Global avian influenza surveillance in wild birds: a strategy to capture viral diversity. Emerg. Infect. Dis., 21, 4, e1-e7. DOI: 10.3201/eid2104.141415.

13. Pittman, M., Laddomada, A., Freigofas, R., Piazza, V., Brouw, A., Brown, I. H., 2007: Surveillance, prevention, and disease management of avian influenza in the European Union. Journal of Wildlife Diseases, 43, S64-S70.

14. Samantha, J. L., Rogier, B., Anne, P., Jill, B., Bányai, K., Boni, M. F., et al., 2016: Role for migratory wild birds in the global spread of avian influenza H5N8. Science, 354, 6309, 213-217. DOI: 10.1126/science.aaf8852.

15. Sekercioglu, C., Wenny, D., Whelan, C., 2016: Why birds matter: bird ecosystem services promote biodiversity and human well-being. In Avian Ecological Function and Ecosystem Services. University of Chicago Press, 1427 E. 60th Street, Chicago, IL 60637 USA.

16. United States Department of Agriculture, 2014: Avian Influenza, USDA (2014). Retrieved Nov. 23, 2016, from http://www. usda.gov/wps/portal/usda/usdahome?contentid=avian_influenza.html.

17. WHO Interim Global Epidemiological Surveillance Standards for Influenza, 2012: WHO Global Technical Consultation: Global Standards and Tools for Influenza Surveillance. Mhttp://www.who.int/influenza/resources/documents/technical_consultation/en/index.html.

18. World Organisation for Animal Health, 2016: Update on Avian Influenza in Animals (types $\mathrm{H5}$ and H7). Retrieved from http://www.oie.int/animal-health-in-the-world/updateon-avian-influenza/2016/.

Received May 7, 2019

Accepted September 2, 2019 